\title{
The Revised Cardiac Risk Index in the new millennium: a single-centre prospective cohort re-evaluation of the original variables in 9,519 consecutive elective surgical patients L'indice de risque cardiaque modifié dans le nouveau millénaire: une réévaluation prospective et unicentrique de cohorte des variables originales chez 9519 patients consécutifs devant subir une chirurgie non urgente
}

\author{
Christopher Davis, BSc • Gordon Tait, PhD • \\ Jo Carroll, RN, BHA - Duminda N. Wijeysundera, MD, PhD • \\ W. Scott Beattie, MD, PhD
}

Received: 21 March 2013/Accepted: 17 June 2013/Published online: 28 June 2013

(C) Canadian Anesthesiologists' Society 2013

\begin{abstract}
Purpose Cardiac complications following non-cardiac surgery are major causes of morbidity and mortality. The Revised Cardiac Risk Index (RCRI) has become a standard for predicting post-surgical cardiac complications. This study re-examined the original six risk factors to confirm their validity in a large modern prospective database.
\end{abstract}

\footnotetext{
Author contributions Christopher Davis organized and performed the analysis, wrote the first draft of the manuscript, and was responsible for major revisions to both the analysis and manuscript. Gordon Tait was responsible for creation of the database and the data integrity. He performed and or supervised quality checks on the data and helped perform the data analysis. Gordon Tait, Jo Carroll, and Duminda N. Wijeysundera made key revisions to the manuscript. Jo Carroll assisted in the creation of the database and quality control of the data. Duminda N. Wijeysundera and W. Scott Beattie were responsible in part for the concept of the study. Duminda $N$. Wijeysundera revised key aspects of the data analysis. W. Scott Beattie was responsible in part for supervision of the project. He obtained funding for the project, helped write all drafts of the manuscript, and made revisions to the data analysis. Dr. Beattie was Mr. Davis's summer elective supervisor. All authors have seen the data analysis and the revised manuscript and vouch for the authenticity of all aspects of this manuscript.
}

G. Tait, PhD $~$ J. Carroll, RN, BHA

D. N. Wijeysundera, MD, PhD · W. S. Beattie, MD, PhD ( $\triangle)$ Department of Anesthesia and Pain Management, University Health Network, 200 Elizabeth Street, Toronto, ON M5G 2C4, Canada

e-mail:scott.beattie@uhn.ca

C. Davis, BSc

Department of Anesthesia, University of Toronto and the Peter Munk Cardiac Centre, Toronto, ON, Canada
Methods Using the definitions in the original risk index, this study included 9,519 patients aged $\geq 50$ undergoing elective non-cardiac surgery with an expected length of stay $\geq$ two days at two major tertiary-care teaching hospitals. The validity of the original predictors was tested in this population using binomial logistic regression modelling, area under the receiver operator curve (ROC) analysis, and the net reclassification index.

Results Rates of major cardiac complications with 0, 1, $2, \geq 3$ of the predictors were $0.5 \%, 2.6 \%, 7.2 \%$, and $14.4 \%$, respectively, in our patient cohort compared with $0.4 \%, 1.1 \%, 4.6 \%$, and $9.7 \%$, respectively, in the original cohort. Similar to the original report, binary logistic regression analysis showed that both preoperative treatment with insulin (odds ratio [OR] 1.4; $95 \%$ confidence interval [CI] 0.7 to 2.6) and preoperative creatinine $>176.8 \mathrm{mmol} \cdot \mathrm{L}^{-1}$ (OR 1.7; 95\% CI 0.8 to 3.6) did not improve the predictive ability of the index. Analysis of the remaining four factors resulted in an area under the curve $(A U C)$ identical to that seen for the reconstructed six-factor RCRI (AUC=0.79). We found that a

D. N. Wijeysundera, MD, $\mathrm{PhD}$

Department of Health Policy Management and Evaluation, Li Ka Shing Knowledge Institute of St. Michael's Hospital, University of Toronto, Toronto, ON, Canada 
glomerular filtration rate $(G F R)<30 \mathrm{~mL} \cdot \mathrm{min}^{-1}$ was a better predictor of major cardiac complications (OR 2.2; $95 \%$ CI 1.2 to 4.3$)$ than creatinine $>176.8 \mathrm{mmol} \cdot \mathrm{L}^{-1}$. The receiver operating characteristic analysis of this resultant 5-Factor model resulted in an AUC of 0.79, with 0, 1 , $2, \geq 3$ of the predictors representing 0.5\%, 2.9\%, 7.4\%, and $17.0 \%$ risk, respectively, among our patient cohort.

Conclusion Compared with the RCRI, a simplified 5-Factor model using a high-risk type of surgery, a history of ischemic heart disease, congestive heart failure, cerebrovascular disease, and a preoperative GFR $<30 \mathrm{~mL} \cdot \mathrm{min}^{-1}$ results in superior prediction of major cardiac complications following elective noncardiac surgery.

\section{Résumé}

Objectif Les complications cardiaques suite à une chirurgie non cardiaque constituent d'importantes causes de morbidité et de mortalité. L'indice de risque cardiaque modifié (IRCM) est devenu un étalon or pour prédire les complications cardiaques après une chirurgie. Cette étude a réévalué les six facteurs de risque originaux afin de confirmer leur validité dans une importante base de données prospective et moderne.

Méthode À l'aide des définitions de l'indice de risque d'origine, cette étude a inclus 9519 patients âgés $\geq 50$ ans subissant une chirurgie non cardiaque non urgente, dont la durée de séjour prévue était de deux jours ou plus dans deux importants hopitaux universitaires de soins tertiaires. La validité des prédicteurs originaux a été testée dans cette population à l'aide d'un modèle de régression logistique binomiale, d'une analyse de la surface sous la courbe $R O C$, et de l'indice NRI (net reclassification index).

Résultats Les taux de complications cardiaques majeures avec $0,1,2, \geq 3$ des prédicteurs étaient de $0,5 \%, 2,6 \%, 7,2 \%$, et 14,4\%, respectivement, dans notre cohorte de patients, comparativement à $0,4 \%, 1,1 \%$, $4,6 \%$, et $9,7 \%$, respectivement, dans la cohorte originale. Tout comme dans le compte rendu original, l'analyse de régression logistique binaire a montré que ni un traitement préopératoire avec de l'insuline (rapport de cotes [RC] 1,4; intervalle de confiance [IC] $95 \%$ 0,7 à 2,6), ni un taux de créatinine préopératoire $>176,8 \mathrm{mmol} \cdot \mathrm{L}^{-1}(\mathrm{RC} 1,7$; IC $95 \%$ 0,8 à 3,6) n'amélioraient la capacité prédictive de l'indice. L'analyse des quatre autres facteurs a donné une surface sous la courbe (SSC) identique à celle observée pour l'IRCM à six facteurs reconstruit $(S S C=0,79)$. Nous avons observé qu'un débit de filtration glomérulaire $(D F G)<30 \mathrm{~mL} \cdot \mathrm{min}^{-1}$ était un meilleur prédicteur de complications cardiaques majeures (RC 2,2; IC $95 \%$ 1,2 à 4,3) qu'un taux de créatinine $>176,8 \mathrm{mmol} \cdot \mathrm{L}^{-1}$. L'analyse de la courbe ROC de ce modèle à 5 facteurs a donné une SSC de 0,79, avec 0, 1, 2, $\geq 3$ prédicteurs représentant un risque de 0,5\%,2,9\%, 7,4\%, et 17,0\%, respectivement, dans notre cohorte de patients.

Conclusion Par rapport à l'IRCM, un modèle simplifié à 5 facteurs utilisant un type de chirurgie à risque élevé, des antécédents de cardiopathie ischémique, une insuffisance cardiaque congestive, une maladie cérébrovasculaire et un DFG préopératoire $<30 \mathrm{~mL} \cdot \mathrm{min}^{-1}$ donne une meilleure prédiction de complications cardiaques majeures après une chirurgie non cardiaque non urgente.

The most frequent cause of postoperative morbidity and mortality is as a direct result of an adverse cardiac event. ${ }^{1}$ This is a major public health issue since mortality rates remain in excess of $2 \%^{1,2}$ in the more than 200 million surgical procedures that occur annually around the world. ${ }^{3}$ In an effort to reduce this burden, the American College of Cardiology/American Heart Association guidelines committee $^{4}$ has adopted the Revised Cardiac Risk Index $(\mathrm{RCRI})^{5}$ to preoperatively identify elective patients at risk of major cardiac complications. The RCRI has subsequently been found to be practicable, accurate, and generalizable. 6

The RCRI was derived from a prospective cohort of elective surgical patients and used creatinine kinase-MB (CK-MB) to identify postoperative cardiac events. The "revised" nomenclature specified that the RCRI built on and simplified an earlier index. ${ }^{7}$ The RCRI was derived from a cohort of 4,315 patients, where 2,893 were used to derive the index, i.e., the "derivation set", and 1,422 patients were assigned to the "validation set". The index is composed of six predictive factors: high-risk type of surgery, history of ischemic heart disease, history of congestive heart failure, history of cerebrovascular disease, preoperative treatment with insulin, and preoperative serum creatinine $>177 \mathrm{mmol} \cdot \mathrm{L}^{-1}$. Each factor in the model is equally weighted with one point assigned per predictor and with increasing point totals corresponding to an increase in the patient's overall postoperative cardiac risk. Interestingly, the risk factors "preoperative treatment with insulin" and "preoperative serum creatinine $>$ $177 \mathrm{mmol} \cdot \mathrm{L}^{-1}$ " did not remain significant in the validation process of the original communication. Nevertheless, these factors were included in the model and have remained in the index because comparison of the odds ratios in the derivation and validations sets were "not statistically different". The original description did show that exclusion of these two factors, i.e., diabetes and chronic renal failure, resulted in a model with superior discrimination. Presently, almost a quarter century after the first patients were entered in the model, use of the RCRI is now widespread. ${ }^{8-11}$ In this interval, the diagnostic criteria 
for myocardial infarction have changed, ${ }^{12}$ and we are unaware of any studies that have re-examined the two factors, diabetes and chronic renal failure. As a result, we submit there is a need to re-examine the accuracy and clinical utility of the index.

The primary objective of this study was to re-examine the validity of the inclusion of the two predictors, diabetes and chronic renal failure, in the RCRI using a large modern prospectively collected data set. Our hypothesis was that neither diabetes nor this definition of chronic renal failure improved the accuracy or discrimination of the RCRI. The secondary objectives of this study were to evaluate alternative definitions of preoperative renal function and diabetes or glucose tolerance on the predictive accuracy of the RCRI.

\section{Methods}

The University Health Network (UHN) Research Ethics Board approved this study and waived the need for informed consent. The UHN is a university-based tertiary care hospital that performs a full range of adult surgical procedures. Our goal a priori was to reproduce, as closely as possible, the conduct of the original investigation. ${ }^{4} \mathrm{We}$ therefore included consecutive elective patients, over the age of 50, who were screened in the preoperative assessment clinic for elective inpatient non-cardiac surgery with a length of stay of at least two days. The preoperative data were prospectively collected from April 1, 2008 to December 31, 2010 and extracted from two separate electronic databases. Preoperative data were collected from our Clinical Anesthesia Information System (CAIS) (Adjuvant Informatics, Freelton, ON, Canada). The CAIS is a standardized web-based preoperative assessment tool developed by the UHN to evaluate all elective surgical patients. Patient information was entered into the CAIS by advanced practice nurses at pre-scheduled appointments. The CAIS collects information using standardized branched logic. The collected data include patient demographics, vital signs, detailed histories (and their treatments), including the components of the RCRI, preoperative lab values, results of noninvasive tests, and a full medication history, including instructions of when to stop or continue the medications. Postoperative data were extracted from the institutional electronic data warehouse (EDW) and included data relating to the surgical procedure, postoperative laboratory values, as well as postoperative patient outcomes. The EDW data are largely obtained from the International Classification of Diseases tenth revision (ICD-10) codes. Myocardial injury was assessed using troponin I on the Abbott ARCHITECT i2000SR ${ }^{\circledR}$ analyzer (Abbott Diagnostics Abbott Park, IL, USA). The peak postoperative troponin level-defined as the highest level at any time postoperative until discharge-was assessed. We have recently shown an error rate of $<2 \%$ in a direct comparison of the patient chart $v s$ the EDW data at the UHN. ${ }^{13}$

During the study period, the UHN preoperative assessment clinics evaluated 15,597 consecutive patients, each having a complete CAIS data set. We excluded 4,073 patients who were under the age of 50 or had either urgent or emergent procedures. A further 2,005 patients were excluded due to a hospital length of stay that was less than two days, leaving a final study population of 9,519 patients. The six RCRI predictors and the outcome variable, major cardiac complications (MCCs), were reconstructed using the original criteria. We therefore defined MCCs using a definition similar to the original RCRI as the postoperative occurrence of any or all of myocardial infarction, pulmonary edema, or primary cardiac arrest. This differs from the primary paper in the following ways:

1) Due to limitations within the CAIS data, a history of paroxysmal nocturnal dyspnea was excluded.

2) The term "pulmonary edema" was based on ICD-10 codes instead of a formal reading of the chest radiograph.

3) The terms "complete heart block" and "ventricular fibrillation" were not available and are thus excluded from the derivation of MCCs (Table 2).

All other predictors used were derived as outlined in the original investigation. Using the reproduced risk predictors, the eligible patients in the study database were then individually categorized as per the RCRI scoring system.

Statistical analysis was conducted with SPSS ${ }^{\circledR}$ version 19 (IBM, Armonk, NY, USA). A reproduced RCRI model using the CAIS data was generated in a fashion identical to the original RCRI using the original predictors and forced entry binary logistic regression. Next, to test the importance of the six factors to the overall quality of the model, a forward conditional entry model was generated, again using binary logistic regression. Finally, the addition of supplementary predictors to the simplified model was tested using individual substitution into the model and a forward conditional build. The candidate variables assessed in this aspect of the analysis were alternative definitions of diabetes. For diabetes, we sequentially assessed the terms "diabetic yes or no", "preoperative glucose $>$ $11.1 \mathrm{mmol} \cdot \mathrm{L}^{-1}$ ", and "glucose categories $(<7.8,7.8$ to 11.1 , and $\left.>11.1 \mathrm{mmol} \cdot \mathrm{L}^{-1}\right)$. For renal failure, we also assessed two levels of glomerular filtration rate (GFR) (30 and $60 \mathrm{~mL} \cdot \mathrm{min}^{-1}$ ), calculated using the Cockcroft-Gault 
Table 1 Study cohort comparison between RCRI and CAIS data: includes percentage breakdown by individual surgical category for the CAIS data

\begin{tabular}{|c|c|c|c|c|c|c|c|c|c|}
\hline & $\begin{array}{l}\text { Women, } \\
\%\end{array}$ & $\begin{array}{l}\text { Mean } \\
\text { age, yr }\end{array}$ & $\begin{array}{l}\text { High Risk } \\
\text { Surgery, }{ }^{1} \%\end{array}$ & $\begin{array}{l}\mathrm{CAD},{ }^{2} \\
\%\end{array}$ & $\begin{array}{l}\text { Diabetes, }{ }^{3} \% \\
\text { (\% on insulin) }\end{array}$ & $\begin{array}{l}\mathrm{CHF}^{4} \\
\%\end{array}$ & $\begin{array}{l}\mathrm{CVD},{ }^{5} \\
\%\end{array}$ & $\begin{array}{l}\text { Renal } \\
\text { Insufficiency, } \\
\%\end{array}$ & $\begin{array}{l}\text { Hypertension, }{ }^{7} \\
\%\end{array}$ \\
\hline Lee et al., 1999 & 51.4 & NR & 32.1 & 33.1 & NR (4.0) & 16.0 & 10.0 & 3.7 & NR \\
\hline CAIS data overall & 48.5 & 66.0 & 26.3 & 18.5 & $17.0(2.4)$ & 3.0 & 7.2 & 1.4 & 52.4 \\
\hline \multicolumn{10}{|l|}{ Surgical Subtype } \\
\hline Abdominal $(n=1,318,14 \%)$ & 47.4 & 65.7 & 97.1 & 18.2 & $22.3(4.7)$ & 3.8 & 6.1 & 1.8 & 51.4 \\
\hline Orthopedic $(n=2,264,24 \%)$ & 60.0 & 67.5 & 0.0 & 17.0 & $15.6(1.2)$ & 2.9 & 5.2 & 0.5 & 56.5 \\
\hline Thoracic $(n=1,011,11 \%)$ & 49.0 & 65.6 & 99.1 & 20.1 & $12.8(1.5)$ & 2.3 & 4.5 & 0.9 & 46.2 \\
\hline Vascular $(n=461,5 \%)$ & 24.5 & 72.0 & 47.1 & 52.7 & $27.5(5.4)$ & 9.8 & 27.5 & 4.8 & 82.0 \\
\hline Other $(n=4,465,47 \%)^{*}$ & 45.4 & 64.9 & 0.0 & 15.5 & $16.0(2.2)$ & 2.2 & 7.1 & 1.4 & 49.0 \\
\hline
\end{tabular}

CAIS = Clinical Anesthesia Information System; RCRI = original dataset for derivation and validation of the Revised Cardiac Risk Index; $\mathrm{NR}=$ not reported

${ }^{1}$ Defined as intraperitoneal, intrathoracic or suprainguinal vascular procedures, cardiac ischemia, use of nitrate therapy

2 Defined as coronary artery disease

${ }^{3}$ Defined as total $\%$ diabetics (CAIS), of this $2.4 \%$ are on insulin therapy (CAIS)

${ }^{4}$ Defined as history of congestive heart failure (CAIS), excluded pulmonary edema on chest $x$-ray, paroxysmal nocturnal dyspnea, physical exam showing bilateral rales or S3 gallop

${ }^{5}$ Cardiovascular disease - defined as history of either stroke or transient ischemic attack (CAIS)

${ }^{6}$ Defined as preoperative serum creatinine $>176.6 \mathrm{mmol} \cdot \mathrm{L}^{-1}$ (CAIS)

${ }^{7}$ Defined as history of hypertension (CAIS) or hypertension requiring medical control of blood pressure (CAIS)

* “Other" category composed of gastrointestinal, ear nose and throat, neurological surgeries

equation. ${ }^{\text {A }}$ The threshold for inclusion was $P<0.05$ for all models generated. The generated models were then compared using receiver operating characteristic (ROC) curves and area under the curve (AUC) analysis and using the net reclassification index. ${ }^{14}$ Odds ratios for each of the original six factors and the additional factors tested were also calculated, and the discrimination of the new models (ROC and $95 \%$ confidence interval [CI]) was compared with those in the original report.

\section{Results}

The two study populations, the original RCRI description of 4,315 elective patients and the CAIS population of 9,519, are compared in Table 1. Of importance is the slightly higher percentage of males in the CAIS data. The original data did not report the mean age of the study population or the percentage of the study population with

\footnotetext{
$\overline{\mathrm{A}}$ The Cockcroft-Gault equation is generated using age, weight, sex, and serum creatinine level glomerular filtration rate $(G F R)=(140-$ age $\times$ weight $[\mathrm{kg}] \times$ constant $) /$ serum creatinine $\left(\right.$ umol $\left.\cdot \mathrm{L}^{-1}\right)$. The constant is 1.23 for men and 1.04 for women. This estimated glomerular filtration rate (eGFR) is automatically calculated in the Clinical Anesthesia Information System using this equation. Available from URL: http://en.wikipedia.org/wiki/Renal_function (accessed May 10, 2013).
}

hypertension. Each of six component risk factors is less frequent in the CAIS data compared with the original description. Table 1 also includes a subset breakdown by surgical classification that is different from the original RCRI data. The present study had more abdominal surgeries but fewer orthopedic and vascular procedures. The category "Other" surgery included genitourinary, neurosurgery, and ear nose and throat surgeries and included significantly more than in the original RCRI manuscript.

The prevalence of MCCs in each of the six component risk factors is compared with the original RCRI in Table 2. The CAIS and RCRI data sets show that events occurred more often in patients with a "history of ischemic heart disease" and "congestive heart failure". The remaining four risk factors had similar rates of MCCs. The rates of myocardial infarction (MI) are measured by troponin I as compared with creatine kinase in the original RCRI description. The terms "complete heart block", which was recorded in only $0.1 \%$ of the RCRI population (4/ $4,315)$, and "ventricular fibrillation", were not available in the CAIS data. Ventricular fibrillation was combined with cardiac arrest in the RCRI data $(0.4 \%, 16 / 4,315)$, but in the CAIS data, cardiac arrest was recorded alone $(0.3 \%$, 34/9,519) (relative risk [RR] 0.96 ; 95\% CI 0.53 to 1.74). The overall rate of MCCs did not differ between the two studies (Table 3). 
Table 2 Comparison of the components of RCRI: CAIS $v s$ original (4): The occurrence of major cardiac complications (MCCs) postoperatively

\begin{tabular}{|c|c|c|c|c|c|}
\hline \multirow[t]{2}{*}{ Revised Cardiac Risk Index: predictors } & \multicolumn{2}{|l|}{ CAIS data } & \multicolumn{2}{|l|}{ RCRI data } & \multirow[t]{2}{*}{ Relative risk of MCCs $(95 \% \mathrm{CI})$} \\
\hline & MCCs / $n$ & $(\%)$ & $\mathrm{MCCs} / n$ & $(\%)$ & \\
\hline 1. High-risk surgery type & $87 / 2,499$ & (3.4) & $27 / 894$ & $(3.0)$ & $1.15(0.75$ to 1.76$)$ \\
\hline 2. History of ischemic heart disease & $104 / 1,762$ & $(5.9)$ & $34 / 951$ & (3.6) & $1.65(1.13$ to 2.41$)$ \\
\hline 3. History of congestive heart failure & $33 / 284$ & $(11.6)$ & $23 / 434$ & $(5.3)$ & $2.12(1.35$ to 3.65$)$ \\
\hline 4. History of cerebrovascular disease & $41 / 685$ & $(6.0)$ & 17 / 291 & $(5.8)$ & $1.02(0.59$ to 1.77$)$ \\
\hline 5. Preoperative treatment with insulin & $12 / 225$ & $(5.3)$ & $7 / 112$ & $(6.3)$ & 0.85 (0.35 to 2.10$)$ \\
\hline 6. Preoperative creatinine $>176 \mathrm{mmol} \cdot \mathrm{L}^{-1}$ & $9 / 131$ & $(6.9)$ & $9 / 103$ & $(8.7)$ & $0.78(0.32$ to 1.91$)$ \\
\hline
\end{tabular}

The relative risk compares the outcomes (MCCs) between CAIS and original data for each component risk factor

RCRI data $=$ original derivation and validation of the Revised Cardiac Risk Index; CAIS = Clinical Anesthesia Information System; $\mathrm{CI}=$ confidence interval

Table 3 Primary outcome: comparison of the components of the composite

*CAIS data did not include ventricular fibrillation data;

CAIS $=$ Clinical Anesthesia Information System; RCRI data $=$ original derivation and validation data for the Revised Cardiac Risk Index

\begin{tabular}{lllr}
\hline Major cardiac complications & $\begin{array}{l}\text { CAIS data } \\
(\text { Total }=9,519) \\
n(\%)\end{array}$ & $\begin{array}{l}\text { RCRI data } \\
(\text { Total }=4,315) \\
n(\%)\end{array}$ & $P$ value \\
\hline Major cardiac complication & $200(2.1)$ & $92(2.1)$ & 0.957 \\
Myocardial infarction & $163(1.7)$ & $46(1.1)$ & 0.005 \\
Pulmonary edema & $19(0.2)$ & $42(1.0)$ & $<0.001$ \\
Cardiac arrest/ventricular & $34(0.3)$ & $16(0.4)$ & 0.795 \\
Fibrillation* & & $4(0.1)$ & \\
Complete heart block & Not Available & & \\
\hline
\end{tabular}

Table 4 Comparison of the original RCRI model with models generated using CAIS data: Individual risk stratification by point score and resultant model AUC

\begin{tabular}{|c|c|c|c|c|c|c|}
\hline \multirow[t]{2}{*}{ Model } & \multicolumn{4}{|c|}{ Events/Total, by Model Score, $n / n(\%)$} & \multirow[t]{2}{*}{ AUC (95\% CI) } & \multirow[t]{2}{*}{ NRI } \\
\hline & 0 Points & 1 Point & 2 Points & $\geq 3$ Points & & \\
\hline RCRI data $1999^{(1)}$ & 7 / 1,559 (0.4) & $19 / 1,673(1.1)$ & $35 / 764(4.6)$ & $31 / 319(9.7)$ & $0.78(0.73$ to 0.82$)$ & \\
\hline CAIS data (Reconstructing RCRI) & $25 / 5,276(0.5)$ & $81 / 3,145(2.6)$ & $65 / 897(7.2)$ & $29 / 201(14.4)$ & $0.79(0.76$ to 0.83$)$ & \\
\hline 4-Factor model* (CAIS data) & 25 / 5,397 (0.5) & 87 / 3,156 (2.8) & $70 / 842(8.3)$ & $18 / 124(14.5)$ & 0.79 (0.76 to 0.82$)$ & $-5.2 \%, P=0.246$ \\
\hline $\begin{array}{l}\text { 5-Factor model (Using } \\
\left.\quad \text { eGFR < } 30 \mathrm{~mL} \cdot \mathrm{min}^{-1}\right) * *\end{array}$ & $21 / 4,446(0.5)$ & 78 / 2,693 (2.9) & $56 / 753(7.4)$ & $23 / 135(17.0)$ & 0.79 (0.75 to 0.82$)$ & $-0.4 \%, P=0.049$ \\
\hline
\end{tabular}

*Original RCRI predictors, including high-risk type of surgery, a history of ischemic heart disease, congestive heart failure, cerebrovascular disease, but removing "insulin therapy for diabetes" and "preoperative serum creatinine $>176.8 \mathrm{mmol} \cdot \mathrm{L}^{-1}$ ",

**4-Factor model with the addition of glomerular filtration rate $(\mathrm{GFR})<30 \mathrm{~mL} \cdot \mathrm{min}^{-1}$. Not all patients had data necessary to calculate GFR $(n=8,027$ used, total MCCs $n=178)$. RCRI = Revised Cardiac Risk Index; CAIS = Clinical Anesthesia Information System; AUC $=$ area under the curve; $\mathrm{CI}=$ confidence interval; $\mathrm{NRI}=$ net reclassification index; eGFR = estimated glomerular filtration rate; The NRI tables are in the Appendix

The rates of MCCs in the original RCRI model were $0.4 \%, 1.1 \%, 4.6 \%$, and $9.7 \%$ for $0,1,2$, and $\geq 3$ points, respectively, with an AUC value of 0.78 (95\% CI 0.73 to 0.82). The comparable rates using the CAIS data were $0.5 \%, 2.6 \%, 7.2 \%$, and $14.4 \%$ risk of MCCs, respectively, for the same categories. The AUC was 0.79 (95\% CI 0.76 to 0.83 ) (Table 4). When the model was re-calculated using forward conditional entry, the terms "insulin therapy for diabetes" and "preoperative creatinine $>176 \mathrm{mmol} \cdot \mathrm{L}^{-1}$ " did not remain in the model, creating the "4-Factor model". The percentages of predicted MCCs by point class remain essentially the same, and the AUC value is unchanged in this model.

Evaluation of the alternative definitions of diabetes and renal failure were attempted after finding that "preoperative treatment with insulin" (odds ratio [OR] 
1.4; $95 \%$ confidence interval $[\mathrm{CI}] 0.7$ to 2.6$)$ and "preoperative creatinine $>177 \mathrm{mmol} \cdot \mathrm{L}^{-1}$ " $(\mathrm{OR} 1.7 ; 95 \%$ CI 0.8 to 3.6) were not significant and did not improve the discrimination of the index. The terms "diabetic yes or no" (OR 1.4; 95\% CI 1.0 to 2.0), "preoperative glucose > $11.1 \mathrm{mmol} \cdot \mathrm{L}^{-1}$ " (OR $1.5 ; 95 \%$ CI 0.8 to 2.6 ), and "glucose categories $\left(<7.8,7.8-11.1,>11.1 \mathrm{mmol} \cdot \mathrm{L}^{-1}\right)$ " (OR $1.2 ; 95 \%$ CI 1.0 to 1.6 ) were evaluated, but none of these definitions improved the discrimination of the index (Table A2). Furthermore, two alternative models were then generated. In the model with five variables, the fifth variable used GFR $<30 \mathrm{~mL} \cdot \mathrm{min}^{-1}$. This model showed the same percent of predicted MCCs as the model without GFR but improved calibration. The relative variances between the RCRI point categories resulting from the above modifications and the original reconstructed RCRI model are detailed in Table A1. The 4-Factor model shifts both MCCs and overall patients in the 2 and $\geq 3$ point categories to lower point ranges and results in no significant change in the net reclassification index. The 5-Factor model with GFR $<30 \mathrm{~mL} \cdot \mathrm{min}^{-1}$ also loses patients from the 2 and $\geq 3$ categories but to a less extent than the 4-Factor model and to a significantly less extent than patients who experienced MCCs in the $\geq 3$ category; therefore, the net reclassification index is marginally improved.

\section{Discussion}

This study reinforces the importance and validity of the RCRI as a means of predicting major cardiac events after elective surgery. Almost two decades later, in spite of rapidly changing surgical techniques ${ }^{15,16}$ and improvements to clinical diagnostic testing, ${ }^{11,17,18}$ the factors identified in the original report are relevant in a modern elective surgical patient population. Through all of the modelling procedures, any combination of the terms (high-risk type of surgery, history of ischemic heart disease, history of congestive heart failure, and history of cerebrovascular disease) remained discriminatory.

The results of the present study are remarkably similar to those in the original description, and in its current form, the model contains two factors, documented in this analysis, that do not improve its risk prediction. As in the original description, the removal of these factors does not affect the final risk stratification or the improved discrimination of the index. A recent large retrospective analysis of the Veterans Affairs Medical Center surgical database also failed to find diabetes as a significant predictor of cardiac outcomes. ${ }^{19}$ Focused attempts to include modified terms related to diabetes mellitus or preoperative blood sugar levels could not significantly improve the ability to predict the risk of MCCs or improve the accuracy or the discrimination of the index. Glycosylated hemoglobin has been advocated as an important risk factor in diabetic outcomes and may be a factor that could potentially improve the index $;{ }^{20-22}$ however, the data in our database were insufficient to assess this variable. In our view, it would be important to drop the diabetes terminology from the RCRI; inclusion has the potential to create patient safety issues. We consider this an important issue, even though investigation shows that inclusion of diabetes does not influence the overall statistical integrity of the predictive model. We do not debate that diabetes continues to be highly associated with cardiac disease, renal failure, and cerebral vascular disease, all of which remain highly predictive of postoperative major cardiac events. When diabetes is the ONLY risk factor, we are concerned that it may lead to an inappropriate intervention. Consider the pay per performance guidelines that were implemented in the USA making beta-blockers a quality of care indicator. In response, all patients with a cardiac risk were required to have beta-blockers administered perioperatively. Subsequently, at least two investigations have shown a $30 \%$ increase in mortality when beta-blockers were administered to patients where diabetes was the ONLY risk factor. ${ }^{9,23}$

Our investigation did identify a potential alternative definition of chronic renal failure, specifically, a preoperative GFR of $<30 \mathrm{~mL} \cdot \mathrm{min}^{-1}$. A reconstituted 5-Factor model, including cardiovascular disease, coronary artery disease, congestive heart failure, high-risk surgery, and GFR $<30 \mathrm{~mL} \cdot \mathrm{min}^{-1}$, maintained the same discrimination value and slightly improved the net reclassification, mostly in patients at higher risk for MCCs. The addition of a calculated GFR of $<60 \mathrm{~mL} \cdot \mathrm{min}^{-1}$ resulted in less improvement in either the discrimination or the calibration. This definition does have the advantage of being the threshold for chronic kidney disease as defined by the National Kidney Foundation. ${ }^{19}$ On the basis of these considerations, we would advocate for a 5-Factor model where the renal component is denoted by a low GFR and diabetes is dropped from the index.

This evaluation of a prospectively collected moderaterisk elective non-cardiac surgical population has several important differences compared with the original population derived for the RCRI. All six RCRI predictors are less prevalent in our study population compared with the original derivation. In addition, the number of patients at lowest risk of MCCs in our evaluation represents $55 \%$ of the study population, whereas this risk stratum represents $27 \%$ of the original study population. In fact, in the original study population, there were more patients in the second risk stratum than in the first. This difference between two consecutive patient populations is difficult to explain; we 
can only reiterate that our series represents a consecutive series of patients from an organized central clinic using a universal web-based interrogation system. In contrast, the original data were derived from several different specialty clinics, resulting in variable entry to the study. Even so, the rate of MCCs are similar in the lowest risk stratum, and the overall rate of MCCs within our data is comparable with that seen in the RCRI data.

There were, however, important differences in the components of the composite outcome. The prevalence of myocardial infarction within the CAIS data was almost twice that seen in the original derivation. We suspect this is related to the use of high-sensitivity serum troponin measurements that are now the gold standard for the diagnosis of perioperative myocardial infarction ${ }^{24,25}$ and superior for the diagnosis of acute myocardial infarction. ${ }^{12}$ The absolute number of pulmonary edema events is the same, but this represents an increased prevalence in our more recent data, since the number of patients with preexisting congestive heart failure is one-quarter that of the original study. This lower incidence of preoperative congestive heart failure likely represents the improved chronic management of cardiac diseases in the 25 years between the two studies. Neither data set can comment on the severity of congestive heart failure; however, we would point out that the highest incidence of pre-existing congestive heart failure is in vascular surgical patients who are a decade older than the other surgical groups. Over this same time period, there have been improvements in perioperative fluid and transfusion therapy that have been shown to improve postoperative outcomes. ${ }^{26}$

The rates of MCCs for each of the RCRI predictive variables show that the rates within the CAIS data are similar to those measured in the original descriptive data. The major differences (outlined above) are shown for "history of ischemic heart disease" and "history of cerebrovascular disease", which are increased in the CAIS data compared with the RCRI data; however, the overall rates are similar.

The surgical subtypes differ from the RCRI data as well. The CAIS data encompass a greater number of "other" surgeries (genitourinary, neurosurgery, and ear nose and throat surgeries), and although the rate of abdominal surgeries is increased, there are fewer orthopedic and vascular procedures than in the RCRI data. This likely represents both a difference in the surgical emphasis at the study hospitals and factors such as vascular surgery and changes in preferred surgical practices over time (endovascular rather than open procedures. ${ }^{7}$ The accuracy and discrimination of vascular surgery in the RCRI has been questioned. A recent meta-analysis ${ }^{3}$ of the RCRI found that the area under curve for RCRI ranged from 0.600.74 with a pooled estimate of 0.64 (95\% CI 0.61 to 0.68$)$, which was less than that found in nonvascular surgery (ROC 0.75 ; 95\% CI 0.72 to 0.79 ) A subgroup analysis in our population found a similar decrease in discrimination (ROC 0.73 for vascular patients compared with ROC 0.79 for non-vascular patients; data not shown).

\section{Limitations}

As outlined, the CAIS data did not include data relating to the outcomes for complete heart block and ventricular fibrillation. Nevertheless, in the original descriptive data, these variables were small contributors to the total prevalence of MCCs and were often present in patients who concurrently suffered one of the other three complications. Also, a few differences existed in the factors used to categorize patients into the six risk predictors as outlined in the Methods section. A major limitation in both the original descriptive study and our study is the lack of universal serial monitoring for cardiac damage. In the original series, creatine kinase surveillance was not universal and measured only in patients who provided a priori consent. In the present study, troponin was systematically measured only in the vascular population, and the remainder of the troponin measurements were based on underlying risk and clinical signs. As a result, troponin was measured more frequently in patients with elevated RCRI scores, and we have previously documented and shown that this clinically based measurement can deliver up to a threefold underestimation of the rate of myocardial damage. ${ }^{20}$

In conclusion, the four validated terms from the original RCRI (i.e., high-risk type of surgery, history of ischemic heart disease, history of congestive heart failure, and history of cerebrovascular disease) should continue to be used to estimate risk and allocate resources in elective surgical patients. The elimination of diabetes from the index would have little effect on the performance of the "index" except to move more patients to a lower risk category. Replacing the term for chronic renal failure with GFR $<30 \mathrm{~mL} \cdot \mathrm{min}^{-1}$ results in a 5-factor index that has good discrimination and better calibration than all other alternatives. Future research should aim to validate these findings within similar consecutive cohorts of elective noncardiac surgery.

Funding The investigation is supported in part by Research and Innovation Funds from the University Health Network Department of Anesthesia and Pain Management. Dr. Beattie is supported by the R. Fraser Elliot Chair in Cardiac Anesthesia Research. Drs Beattie and Wijeysundera receive funding support from the University of Toronto, Department of Anesthesia Merit Awards. Mr. Davis is a medical student at the University of Toronto, and this manuscript is the culmination of a summer project in 2011 . The work was presented in abstract form at the June 2012 Canadian Anesthesiologists' Society Annual Meeting in Quebec City. 
Competing interests The Department of Anesthesia Research and Innovation Fund has received donations from Abbott Corp, BMS, Baxter, Bayer, Fresenius Kabi, and GE Healthcare. None of these companies have participated in the any aspect of this report.

\section{Appendix}

Table A1 Reclassification comparison between the six-variable RCRI model and the model derived from the significant 4-Factors $(n=9,519)$

\begin{tabular}{|c|c|c|c|c|c|c|c|c|c|}
\hline \multirow[t]{2}{*}{ Original model (6 factors) } & & \multicolumn{4}{|c|}{ Patients with MCCs } & \multicolumn{4}{|c|}{ Patients without MCCs } \\
\hline & & RCRI 0 & RCRI 1 & RCRI 2 & $\mathrm{RCRI} \geq 3$ & RCRI 0 & RCRI 1 & RCRI 2 & $\mathrm{RCRI} \geq 3$ \\
\hline \multirow[t]{4}{*}{ 4-Factor model } & 0 & 25 & 0 & 0 & 0 & 5,251 & 116 & 5 & 0 \\
\hline & 1 & 0 & 81 & 6 & 0 & 0 & 2,948 & 117 & 4 \\
\hline & 2 & 0 & 0 & 59 & 11 & 0 & 0 & 710 & 62 \\
\hline & $\geq 3$ & 0 & 0 & 0 & 18 & 0 & 0 & 0 & 106 \\
\hline
\end{tabular}

The net reclassification index is the sum of the patients who had MCCs correctly reclassified to a higher risk category $(-17 / 200=-8.5 \%)$ and the patients without MCCs correctly changed to a lower risk category $(304 / 9,319=3.3 \%)$

Reclassification index for the 4-Factor model was $-5.2 \%(P=0.246)$. RCRI $=$ Revised Cardiac Risk Index; MCCs $=$ major cardiac complications

Table A2 Reclassification comparison between the six-variable RCRI model and the model derived from the 5-Factors with GFR $<30 \mathrm{~mL} \cdot \mathrm{min}^{-1}(n=8,027)$

\begin{tabular}{|c|c|c|c|c|c|c|c|c|c|}
\hline \multirow[t]{2}{*}{ Original model (6 factors) } & & \multicolumn{4}{|c|}{ Patients with MCCs } & \multicolumn{4}{|c|}{ Patients without MCCs } \\
\hline & & RCRI 0 & RCRI 1 & RCRI 2 & $\mathrm{RCRI} \geq 3$ & RCRI 0 & RCRI 1 & RCRI 2 & $\mathrm{RCRI} \geq 3$ \\
\hline \multirow{4}{*}{$\begin{array}{l}\text { 5-Factor model } \\
\quad\left(\text { GFR }<30 \mathrm{~mL} \cdot \mathrm{min}^{-1}\right)\end{array}$} & 0 & 21 & 0 & 0 & 0 & 4,353 & 70 & 2 & 0 \\
\hline & 1 & 1 & 74 & 3 & 0 & 20 & 2,514 & 80 & 1 \\
\hline & 2 & 0 & 0 & 50 & 6 & 0 & 23 & 630 & 44 \\
\hline & $\geq 3$ & 0 & 0 & 4 & 19 & 0 & 0 & 9 & 103 \\
\hline
\end{tabular}

The net reclassification index is the sum of the patients who had MCCs correctly reclassified to a higher risk category $(-4 / 178=-2.2 \%)$ and the patients without MCCs correctly changed to a lower risk category $(145 / 7,849=1.8 \%)$. Reclassification index for the 5-Factor model was $0.4 \%(P=0.049)$

RCRI = Revised Cardiac Risk Index; MCCs = major cardiac complications; GFR = glomerular filtration rate

\section{References}

1. Vascular Events In Noncardiac Surgery Patients Cohort Evaluation (VISION) Study Investigators; Devereaux PJ, Chan MT, Alonso-Coello P, et al. Association between postoperative troponin levels and 30-day mortality among patients undergoing noncardiac surgery. JAMA 2012; 307: 2295-304.

2. Pearse RM, Moreno RP, Bauer $P$, et al. Mortality after surgery in Europe: a 7 day cohort study. Lancet 2012; 380: 1059-65.

3. Weiser TG, Regenbogen SE, Thompson KD, et al. An estimation of the global volume of surgery: a modelling strategy based on available data. Lancet 2008; 372: 139-44.

4. American College of Cardiology Foundation/American Heart Association Task Force on Practice Guidelines; American Society of Echocardiography; American Society of Nuclear Cardiology; Heart Rhythm Society; Society of Cardiovascular Anesthesiologists; Society for Cardiovascular Angiography and
Interventions; Society for Vascular Medicine; Society for Vascular Surgery; Fleisher LA, Beckman JA, Brown KA, et al. 2009 ACCF/AHA focused update on perioperative beta blockade incorporated into the ACC/AHA 2007 guidelines on perioperative cardiovascular evaluation and care for noncardiac surgery. J Am Coll Cardiol 2009; 54: e13-e118.

5. Lee TH, Marcantonio ER, Mangione CM, et al. Derivation and prospective validation of a simple index for prediction of cardiac risk of major noncardiac surgery. Circulation 1999; 100: 1043-9.

6. Ford MK, Beattie WS, Wijeysundera DN. Systematic review: prediction of perioperative cardiac complications and mortality by the revised cardiac risk index. Ann Intern Med 2010; 152: 26-35.

7. Goldman L, Caldera DL, Southwick FS, et al. Cardiac risk factors and complications in non-cardiac surgery. Medicine (Baltimore) 1978; 57: 357-70. 
8. Yang H, Raymer K, Butler R, Parlow J, Roberts $R$. The effects of perioperative beta-blockade: results of the Metoprolol after Vascular Surgery (MaVS) study, a randomized controlled trial. Am Heart J 2006; 152: 983-90.

9. Lindenauer PK, Pekow P, Wang K, Mamidi DK, Gutierrez B, Benjamin EM. Perioperative beta-blocker therapy and mortality after major noncardiac surgery. N Engl J Med 2005; 353: 349-61.

10. Rodseth RN, Lurati Buse GA, Bolliger D, et al. The predictive ability of pre-operative B-type natriuretic peptide in vascular patients for major adverse cardiac events: an individual patient data meta-analysis. J Am Coll Cardiol 2011; 58: 522-9.

11. Wijeysundera DN, Beattie WS, Austin PC, Hux JE, Laupacis A. Non-invasive cardiac stress testing before elective major noncardiac surgery: population based cohort study. BMJ 2010; 340: b5526.

12. Thygesen K, Alpert JS, Jaffe AS, et al. Third universal definition of myocardial infarction. Circulation 2012; 126: 2020-35.

13. Grewal K, Wijeysundera DN, Carroll J, Tait G, Beattie WS. Gender differences in mortality following non-cardiovascular surgery: an observational study. Can J Anesth 2012; 59: 255-62.

14. Pencina MJ, D'Agostino RB Sr, Steyerberg EW. Extensions of net reclassification improvement calculations to measure usefulness of new biomarkers. Stat Med 2011; 30: 11-21.

15. Robinson CN, Balentine CJ, Marshall CL, et al. Minimally invasive surgery improves short-term outcomes in elderly colorectal cancer patients. J Surg Res 2011; 166: 182-8.

16. Giles KA, Pomposelli F, Hamdan A, Wyers M, Jhaveri A, Schermerhorn $M L$. Decrease in total aneurysm-related deaths in the era of endovascular aneurysm repair. J Vasc Surg 2009; 49: 543-50.

17. Beattie WS, Karkouti K, Wijeysundera DN, Tait G. Risk associated with preoperative anemia in noncardiac surgery: a single-center cohort study. Anesthesiology 2009; 110: 574-81.

18. Beattie WS, Abdelnaem E, Wijeysundera DN, Buckley DN. A metaanalytic comparison of preoperative stress echocardiography and nuclear scintigraphy imaging. Anesth Analg 2006; 102: 8-16.
19. London MJ, Hur K, Schwartz GG, Henderson WG. Association of perioperative beta-blockade with mortality and cardiovascular morbidity following major noncardiac surgery. JAMA 2013; 309: 1704-13.

20. Barry WH, Zhang XQ, Halkos $M E$, et al. Nonanticoagulant heparin reduces myocyte $\mathrm{Na}+$ and $\mathrm{Ca} 2+$ loading during simulated ischemia and decreases reperfusion injury. Am J Physiol Heart Circ Physiol 2010; 298: H102-11.

21. Letourneau J, Bui H, Schricker T, Hatzakorzian R. HbA1c: a prognostic biomarker in the surgical and critically ill patient population. J Cardiothorac Vasc Anesth 2012; DOI: 10.1053/ j.jvca.2012.06.030.

22. Halkos ME, Puskas JD, Lattouf OM, et al. Elevated preoperative hemoglobin A1c level is predictive of adverse events after coronary artery bypass surgery. J Thorac Cardiovasc Surg 2008; 136: 631-40.

23. Juul AB, Wetterslev J, Gluud C, et al. Effect of perioperative beta blockade in patients with diabetes undergoing major non-cardiac surgery: randomised placebo controlled, blinded multicentre trial. BMJ 2006; 332: 1482.

24. Levy M, Heels-Ansdell D, Hiralal R, et al. Prognostic value of troponin and creatine kinase muscle and brain isoenzyme measurement after noncardiac surgery: a systematic review and meta-analysis. Anesthesiology 2011; 114: 796-806.

25. Beattie WS, Karkouti K, Tait $G$, et al. Use of clinically based troponin underestimates the cardiac injury in non-cardiac surgery: a single centre cohort study in 51,701 consecutive patients. Can J Anesth 2012; 59: 1013-22.

26. Hamilton MA, Cecconi M, Rhodes A. A systematic review and meta-analysis on the use of preemptive hemodynamic intervention to improve postoperative outcomes in moderate and high-risk surgical patients. Anesth Analg 2011; 112: 1392-402. 